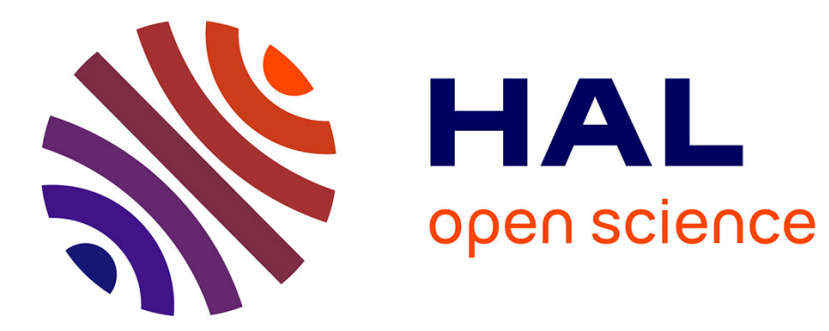

\title{
Cracks detection by a moving photothermal probe
}

J. Bodnar, M. Egée, C. Menu, R. Besnard, A. Le Blanc, M. Pigeon, J. Sellier

\section{To cite this version:}

J. Bodnar, M. Egée, C. Menu, R. Besnard, A. Le Blanc, et al.. Cracks detection by a moving photothermal probe. Journal de Physique IV Proceedings, 1994, 04 (C7), pp.C7-591 -C7-594. 10.1051/jp4:19947139 . jpa-00253194

\section{HAL Id: jpa-00253194 https://hal.science/jpa-00253194}

Submitted on 1 Jan 1994

HAL is a multi-disciplinary open access archive for the deposit and dissemination of scientific research documents, whether they are published or not. The documents may come from teaching and research institutions in France or abroad, or from public or private research centers.
L'archive ouverte pluridisciplinaire HAL, est destinée au dépôt et à la diffusion de documents scientifiques de niveau recherche, publiés ou non, émanant des établissements d'enseignement et de recherche français ou étrangers, des laboratoires publics ou privés. 


\title{
Cracks detection by a moving photothermal probe
}

\author{
J.L. Bodnar, M. Egée, C. Menu, R. Besnard*, A. Le Blanc*, M. Pigeon* and J.Y. Sellier** \\ GRSM/SUE/LEO, Faculté des Sciences, BP. 347, 51062 Reims cedex, France \\ * CEA, CEN Saclay, CEREMIDTM/STA/LCME, 91191 Gif-sur-Yvette cedex, France \\ ** INTERCONTROLE, Sillic, 13 rue du Capricorne, 94150 Rungis cedex, France
}

\begin{abstract}
Using a mobile photothermal probe we show that it is possible to detect rapidly different type of cracks (emerging ones or not), their width being a few micrometers and their depth being some hundredths of micrometers.
\end{abstract}

\section{INTRODUCTION}

Photothermal radiometry is a non destructive testing technique that owes its development to recent technological advances in the domain of optics (laser sources and infrared detectors), of electronics (data acquisition and real-time treatments), and computer engineering.

Its principle consists in exposing a sample to a luminous excitation, and then observing the induced temperature increase by an infrared detection chain. Modulated or pulsed excitation are generally used, but one can choose non conventional methods such as pseudo-random. The photothermal signal depends on the optical and the thermophysical properties of the sample, as well as its structure (presence or not of defects).

Photothermal radiometry is non destructive (the temperature of the sample studied is usually low increasing), contactless (optics excitation and radiometric detection) and only one side of the sample needs to be accessible. These properties make the photothermal radiometry, a method of analysis that is well adapted for industrial use.

Several studies have already been published concerning the use of photothermal radiometry to detect emerging cracks $[1-6,10]$, but only few papers have been dealt with the non emerging ones detection and the characterization aspect $[6,7,10]$. So it was interesting for our team to explore this two latter directions.

With this aim in view, we designed and built a laboratory equipment allowing an analysis of various type of cracks (emerging ones or not) and permitting a fine studying (at a scale of a few tens of micrometers) of the modifications of the photothermal signal induced by the defects (in order to highlight the respective influences of optical and thermal terms on the signal construction and so to make easier in the future, the cracks characterization). We present, hereafter, some results obtained with this latter system, in the case of emerging cracks in reflecting or non reflecting material, and non emerging ones.

\section{DESCRIPTION OF THE EXPERIMENTAL SET-UP}

The experimental set-up device applies the flying spot laser technique [8-10]. The excitation is then produced by a laser beam scanning the surface of the analysed sample. This luminous beam is focalized, deflected at a speed varying between 3 and $6 \mathrm{~cm} / \mathrm{s}$, and illuminates the surface of the sample with an oblique angle. The radiometric detection is assumed by an inf rared camera, equipped with a microscope lens so as to permit one to obtain a fine optical resolution (See figure 1). In order to obtain a sufficient temporal resolution, this camera is moreover used in line scanning mode (note that consequently, the thermogram obtained, now called synthetic thermogram, does not represent a picture of the thermal scene, but the temporal evolution of the signal coming from the same spatial line of the sample). 


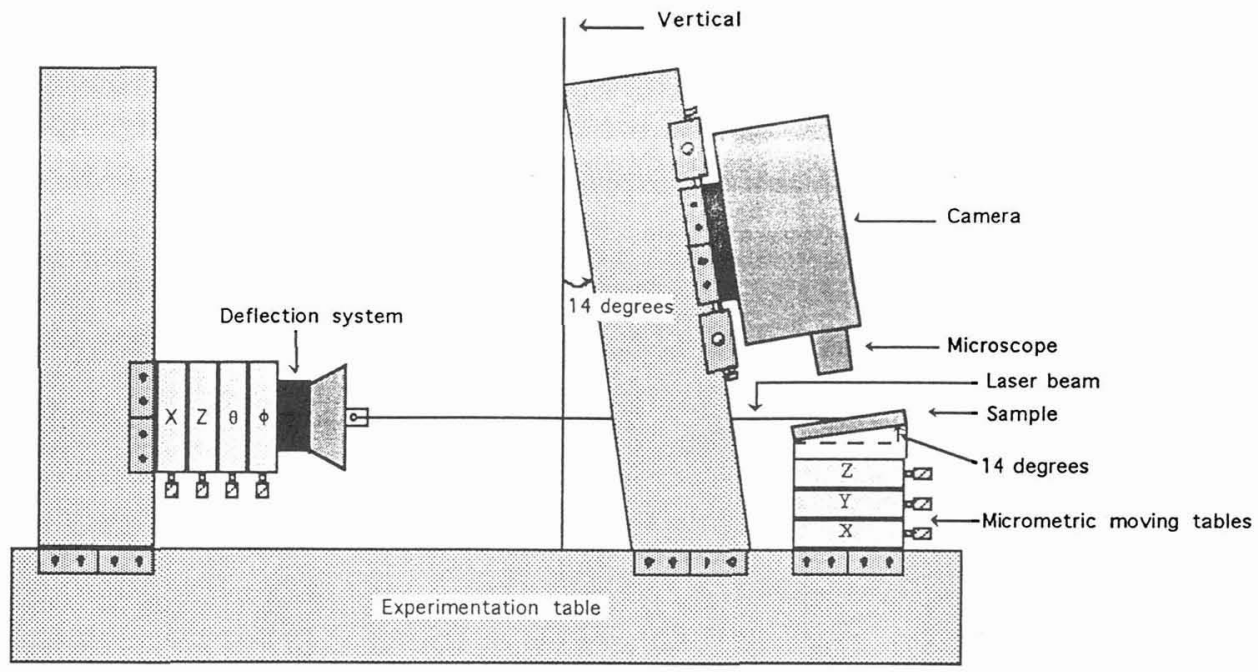

Figure 1 : The experimental equipment used

The experimental procedure used, consists in moving the laser spot, step by step in synchronism with the horizontal motor of the infrared camera, along a line that is perpendicular to the crack, of a distance corresponding to the elementary field-of-view of a pixel, and at each step in acquiring a line of the synthetic thermogram. In this case, along the main diagonal of the synthetic thermogram, we obtain the instantaneous photothermal responses of successively excited surface elements; Along the upper and the lower diagonals, we obtain the photothermal responses of the successive surface elements of the sample, before and after being excited by the mobile light spot (in the first case the detection precedes the excitation, in the second case, the detection follows the excitation).

Such a procedure first allows to obtain a flying spot type analysis without a true mobile instrument. In a second time, it allows to get a synthetic thermogram rich in informations, because giving access simultaneously (by the different diagonals of the picture) to the results that would be produced by different experimental configurations which could be considered for the excitation / detection couple.

\section{RESULTS OBTAINED}

The first synthetic thermogram (figure 2) is a $3 \mathrm{D}$ perspective obtained on a nondefective sample. Due to the increase of temperature accompanying the laser beam, it is characterized by a higher thermosignal value, on a trajectory close to the main diagonal. This general aspect is characteristic of a non defective sample study.

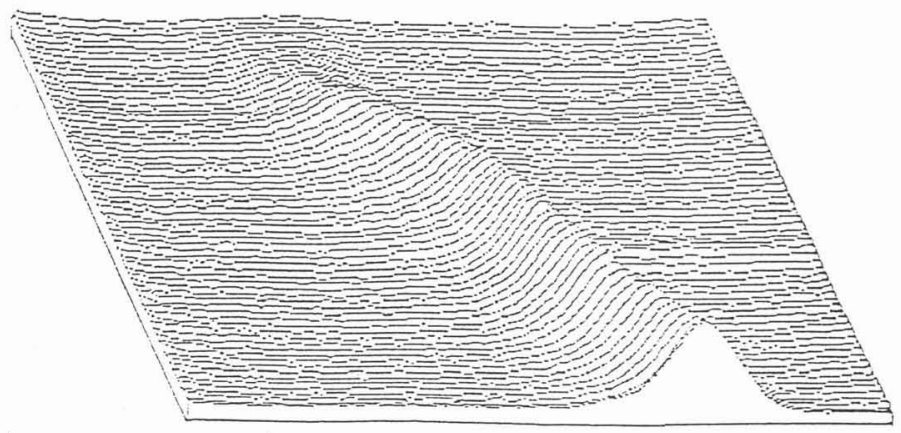

Figure 2: Synthetic thermogram obtained with a non defective sample 
The second synthetic thermogram (figure 3 ) was obtained with an emerging crack on a reflecting surface. In this case, one does not observe a higher signal on a diagonal, but rather on a vertical line. This latter result is due to the radiative properties that are different above the crack and directly on the material. The defect $(5 \mu \mathrm{m}$ wide and $100 \mu \mathrm{m}$ deep) can be considered as a micro black body with an emissivity close to 1 , whereas the emissivity of the material itself is only 0,05 . For the same surface temperature, the radiative energy emitted by the crack is about 20 times higher than the one emitted by the material. This explains the vertical upper signal line.

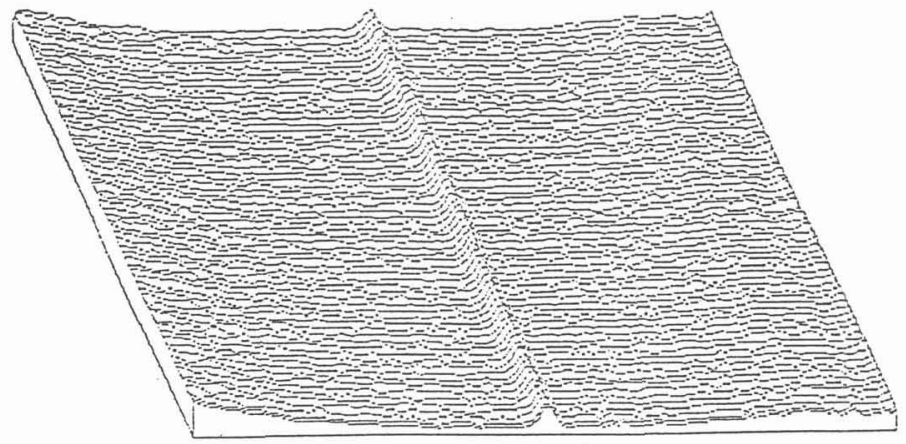

Figure 3 : Synthetic thermogram obtained with a reflecting sample containing an emerging crack (5 $\mu \mathrm{m}$ of width, $100 \mu \mathrm{m}$ of depth)

Figure 4 was obtained when studying an emerging crack on a non reflecting surface. It is characterized by a diagonal band of high value thermosignals, cut by a vertical band of lower values. It should be further noted that the thermosignals are asymmetrical on either side of the diagonal band. This phenomenon shows that such a crack induces two types of disturbances : an optical effect and a thermal effect.

The crack, with its lower thermal conductivity, tends to diminish the heat flux passing through it. When the excitation beam is close to the crack, this is characterized by a relative increase of the photothermal signal on the side where the beam is present, and a relative decrease of signal on the opposite side. This explains the asymmetrical distribution of signal observed on the diagonal band.

The optical effect is due to the simultaneous influence of the oblique excitation angle, and of the important depth of the crack. When the beam illuminates the crack, the energy is absorbed deep inside, on a zone that is not exactly in coincidence with the analysed line. The portion of crack seen by the camera is consequently less heated, leading to lower thermosignal values above the crack.

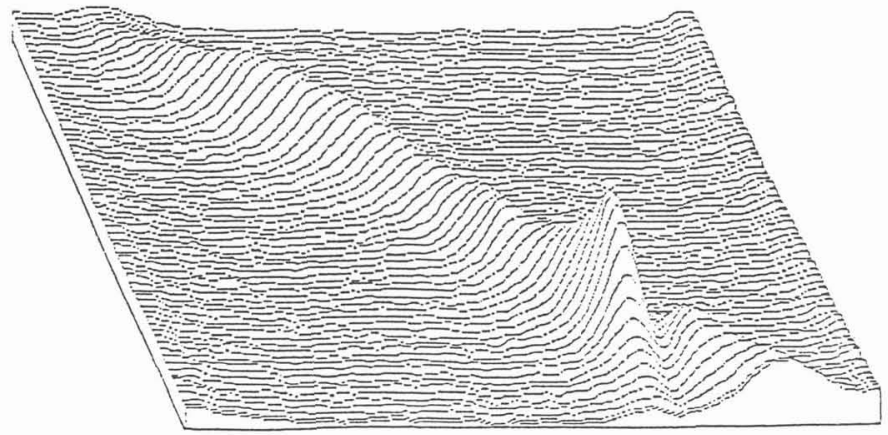

Figure 4 : Synthetic thermogram obtained with a non reflecting sample containing an emerging crack $(60 \mu \mathrm{m}$ of width, $5 \mathrm{~mm}$ of depth) 
The last image (Figure 5) concerns non-emerging cracks (metal coated with a dielectric layer). It shows two bands of high thermosignal values : the first one being diagonal, and the second being vertical, but of half the height. Furthermore, a peak appears at the crossing of these two bands. The diagonal band has the same origin as the one described on figure 2 : it is due to the temperature increase accompanying the laser beam at the outer-surface of the material. The two characteristics of this synthetic thermogram are due to the vertical thermal barrier induced by the crack. The peak of signal is due to the higher increase of the coating temperature, when the spot is right above the crack. The half vertical band is due to the lower decrease of the coating temperature, when the luminous spot is moving away from the defect.

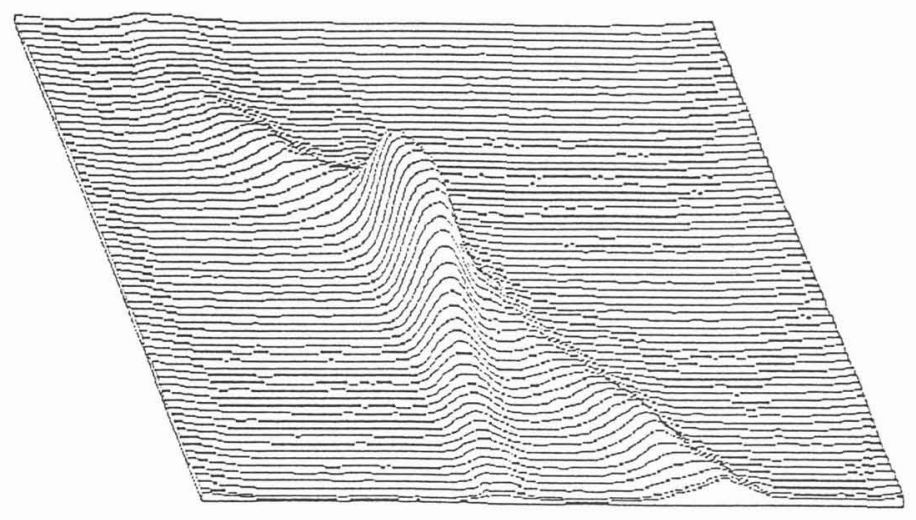

Figure 5 : Synthetic thermogram obtained with a sample containing a non emerging crack $(100 \mu \mathrm{m}$ of width and $5 \mathrm{~mm}$ of depth)

\section{CONCLUSION}

Due to this study, we can say that the method, as well as the equipment, allows for the rapid detection of various type of cracks : emerging at the surface of reflecting or non-reflecting materials, and non emerging.

We can also underline the interesting possibilities of this laboratory equipment, that permit at a fine scale, a complete visualization of the thermal and optical effects due to different types of cracks.

At last, with this laboratory equipment, and the informations it is able to provide, it seems possible to appoach the dimensional characterization of the defects.

It is in this direction that we are currently working.

\section{References}

Periodicals: [1] Y.H. Wong et al : Appl. Phys. Lett. 32, 538 (1978).

Periodicals: [2] J.C. Murphy : Appl. Phys. Lett. 39, 519 (1981).

Periodicals: [3] P.K. Kuo et al : J. Appl. Phys. 53, 1258 (1982).

Periodicals: [4] K.R. Grice et al : J. Appl. Phys. 54, 6245 (1983).

Conference Proceeding: [5] I.Kaufman et al : 5th pan pacific conf on NDT, 1987, p 410-421.

Conference Proceeding: [6] J.L. Bodnar et al : WOM 93, april 1993, pp 590-592.

Conference Proceeding: [7] A. C. Boccara et al : QIRT 92, july 1992, France.

Periodicals: [8] J. Hartikainen, Rev. Sci. Instr. 60, 670 (1989).

Periodicals: [9] Y.Q. Wang et al : photoacoustic and photothemal phenomena, 1990, 62,p24-26.

Thesis: [10] J.L.Bodnar : University of Reims (France), september 1993. 